\begin{tabular}{|c|c|c|}
\hline \multicolumn{3}{|c|}{$\begin{array}{l}\text { OPEN } \text { ठे ACCESS Freely available online } \\
\text { http://www.banglajol.info/index.php/BJID/index } \\
\text { Perspective }\end{array}$} \\
\hline Bangladesh Jc & 1 of Infectious Diseases & \\
\hline October 2020, Volume & er Suppl_2, Page S69-S71 & \\
\hline $\begin{array}{l}\text { ISSN (Online) 2411-670X } \\
\text { ISSN (Print) 2411-4820 }\end{array}$ & DOI: https://doi.org/10.3329/bjid.v7i00.50168 & $=$ \\
\hline
\end{tabular}

\title{
Challenge of Neurosurgical Practices during Covid-19 Pandemic
}

\author{
Kaisar Haroon ${ }^{1}$, Tania Taher ${ }^{2}$, Md. Shafiul Alam³ ${ }^{3}$ Md. Farhad Ahmed ${ }^{4}$
}

\begin{abstract}
${ }^{1}$ Assistant Professor, Department of Neurosurgery, National Institute of Neurosciences \& Hospital, Dhaka, Bangladesh; ${ }^{2}$ Assistant Professor, Holy family Red Crescent Medical College Hospital, Dhaka, Bangladesh; ${ }^{3}$ Associate Professor, Department of Neurosurgery, National Institute of Neurosciences \& Hospital, Dhaka, Bangladesh; ${ }^{4}$ Medical Officer, Department of Neurosurgery, National Institute of Neurosciences \& Hospital, Dhaka, Bangladesh
\end{abstract}

[Received: 17 August 2020; Accepted: 28 September 2020]

\begin{abstract}
The COVID 19 pandemic has changed the world forever. As healthcare facilities were struggling to care for the infected patients, neurosurgeons had to postpone routine surgeries and continue with emergency procedures. They had to take unprecedented measures of protection. The safety and protective measures observed in the hospital for about five months were recorded. These measures were on effect all these time. COVID 19 is very contagious. The preventive and disinfection measures changed our way of consultation in OPD, admission in the wards and surgical and post-operative measures. This changed the practice in our institution. In this paper we look at how the pandemic had changed our practice of neurosurgery. [Bangladesh Journal of Infectious Diseases, October 2020;7(suppl_2):S69-S71]

Keywords: COVID 19; Coronavirus; SARS CoV-2; subdural empyema

Correspondence: Dr. Kaisar Haroon, Assistant Professor, Department of Neurosurgery, NINS. Email: kaisar298@yahoo.com, Phone +01711196577, ORCID: 0000-0002-3065-7877.

Conflict of interest: The author declared no conflicts of interest.

Funding agency: This letter did not receive any specific grant from funding agencies in the public, commercial or not-for-profit sectors.

Contribution to authors: All Authors have done write up.

How to cite this article: Haroon K, Taher T, Alam MS, Ahmed MF. Challenge of Neurosurgical Practices during Covid-19 Pandemic. Bangladesh J Infect Dis 2020;7(suppl_2):S69-S71

Copyright: $\odot 2020$. Haroon et al. Published by Bangladesh Journal of Infectious Diseases. This article is published under the Creative Commons CC BY-NC License (https://creativecommons.org/licenses/by-nc/4.0/). This license permits use, distribution and reproduction in any medium, provided the original work is properly cited, and is not used for commercial purposes.
\end{abstract}

\section{Introduction}

On January 8, 2020, a prescient scientific article was submitted for publication to the Journal of Travel Medicine on a pneumonia of unknown etiology that was identified in patients in Wuhan, China, and the potential for its international spread through commercial air travel ${ }^{1}$.

Coronavirus disease (COVID-19) is an extremely infectious and life-threatening viral illness that gave rise to the current pandemic; an overwhelming healthcare crisis putting the healthcare system under huge strain. COVID-19 outbreak has also brought along disastrous socio-economic effects and heavily impacted healthcare activities including our neurosurgical field ${ }^{2}$. Neurosurgeons have been sheltered from "frontline action" that is battering subspecialists in emergency, intensive care and pulmonary medicine, but nevertheless, the practice of neurosurgery is yet susceptible to the havoc that COVID-19 has wrought ${ }^{3}$. However, neurosurgeons 
has to treat COVID 19 patients as directly or after being reassigned like in Lombardy, northern Italy ${ }^{4}$. In Wuhan, China 9 teams are led by neurosurgeons. Of them, professor Zhiming Liu, a distinguished Chinese neurosurgeon as well as the president of Wuchang Hospital in Wuhan had died ${ }^{5}$.

In neurosurgery, aerosol-generating procedures such as endonasal and anterior skull base surgery present the highest risk for COVID-19 exposure ${ }^{6}$. Also the use of craniotomes and drills cause dust and aerosol to spread to the surroundings. Therefore, the doctors and OT personnel are directly in contact of the virus.

\section{Experience of a Case}

A 13 years old girl presented to us with the complaints of headache for 14 days, fever for 7 days, convulsion once, blurring of vision for 7 days and vomiting for last 3 days just prior to admission. She was reasonably well 7 days before. Than the symptoms appeared and she rapidly became ill. This happened at the last week of April 2020. The COVID 19 pandemic was highest during that time in Dhaka, Bangladesh. She was suspected of COVID 19 and a sample was sent urgently for RT-PCR for COVID 19 which was negative. Her CT scan of brain with contrast had shown that she was suffering from acute subdural empyema. This means that there was pus under the dura mater. It is a neurosurgical emergency which demands urgent evacuation of the pus. In the meantime her condition had deteriorated and emergency evacuation of the empyema was undertaken. Then she developed symptoms of fever and rhinorrhea and therefore a second sample for RT-PCR for COVID 19 was sent. This time report was positive for COVID 19 . Learning this, the whole team of care givers were isolated and they underwent test for COVID 19. Of them, 5 neurosurgeons, 3 nurses from Ward and OT, and 2 ward boys were positive. The OT suit had to be fumigated, the general wards had to be disinfected and other patients needed to be separated and tested. The patient herself now had no neurological problem, so she was referred to a dedicated COVID 19 hospital. She had an uneventful recovery and had recovered completely from both COVID 19 and the subdural empyema.

\section{Discussion}

This above case illustrates the dilemma neurosurgeons are facing with saving the patient and also the risk of contracting the highly contagious disease. A single patient with COVID 19 has infected several caregivers and changed the neurosurgical practice in the hospital. All the persons coming into contact with the patient had to be screened. A total of 26 persons including doctors, nurses, ward boys, OT attendants were tested. Of them 10 had tested positive. The ward where the patient was admitted had to be emptied and fumigated. The admitted patients were moved to other wards and tested for COVID 19.

We have adopted the following procedures in our hospital.

Social measures: In our outpatient department we were taking extra precaution. The doctors, healthcare workers, patients and their attendants were wearing masks and maintaining social distancing. The attending doctors were maintaining distances and postponed the routine case admission. Neurosurgical emergencies were admitted and treated.

Covid 19 tests: All patients coming to the OPD were needed to take COVID 19 tests before admission. Those who were admitted were would take the test again before surgery. Many patient were detected after admission, and then they were treated in dedicated hospital. Those patients who were admitted without tests were admitted in a separate observation ward and then tested. The emergency patients were exempted from this and were treated under strict protection. Our centers required preoperative COVID testing of all patients to eliminate risk. This is also done in the US ${ }^{7}$.

Routine Non-Emergency Procedure: during the COVID 19 period the number of patients had increased. The government of Bangladesh had impose many restrictions to protect the non-infected and minimize community transmission. Therefore we had also deferred routine non-emergency non-life threatening neurosurgical conditions for later surgery. On March 13, 2020, the American College of Surgeons (ACS) issued an unprecedented recommendation to "minimize, postpone or cancel electively scheduled operations"3. We were following the same guideline.

Protective Equipment: Current recommendations allow wearing each mask for more than one patient and using a regular surgical mask over the N95 to avoid droplet soiling. Re-sterilization of these masks is the exception so far. At most, appropriate personal protective equipment (PPE), such as N95 masks or powered air-purifying respirator (PAPR) units, for OR personnel, reduced physician and nursing staffing, and negative-pressure rooms or antechambers are required in varying combinations 
by most centers ${ }^{7}$. N 95 masks were scarce and very costly. So most of the time we used two or three surgical masks and face shield during surgery. Full protective coveralls were cumbersome to use during surgery. Some persons used it by themselves.

Disinfection, sterilizing techniques: For achieving disinfection everybody entering the hospital were checked for fever .there was ample use of antiseptic solution and soap washing. Wards were more thoroughly cleaned and fumigated if there was positive cases. For this reason a new observation ward was arranged. OT complexes were regularly sterilized. Surgical instruments were autoclaved twice after each use.

Telemedicine: The benefits of telemedicine for patients are numerous: it allows patients to avoid missing work, avoids inconveniencing a family member if needed for assistance, and avoids a potentially long commute with associated costs. Telemedicine not only improves clinic efficiency and patient satisfaction but also optimizes the surgeon's schedule. Surgeons can spread out their telemedicine visits throughout the week including early morning and evening ${ }^{8}$. This has become the norm for us as we encourage our patients to contact us through mobile phones and also using the messaging apps.

Residents' Training: The American Board of Neurological Surgery has postponed both primary and oral examinations ${ }^{9}$. In our institution the residents were given a smaller workload, their examinations were deferred and they were given duties for helping Covid19 patients. They were also encouraged to attend the academic webinars ${ }^{10}$, as large gathering, didactic lectures and grand rounds were cancelled during this period.

Operative Volume: During the COVID period, the operation volume dropped significantly in our hospital. This in part due to reduced surgery to reduce infection and also due to the fact that doctors were reallocated to the COVID hospitals for special duties. The number of surgeries went down from 2428 per week to 7-8 per week. It is also seen in other studies $^{3}$. Trans-sphenoidal procedure were also deferred during this time.

Operating Instruments: Powered instruments had been shown to generate blood-containing aerosols with a concentration of hemoglobin detected in the ambient air. Viruses, including human immunodeficiency virus-1 (HIV-1), was demonstrated to be viable in the aerosols generated by surgical power instruments ${ }^{11}$. The use of debriders and drills within the nasal cavity will produce a highly dangerous droplet aerosol ${ }^{12}$. Therefore we avoided using powered instrument as much as possible.

\section{Conclusion}

COVID -19 is caused by corona virus, which is very contagious and deadly to some extent. But it is not to be feared. The virus is mutating and the symptoms and signs are evolving. We have to learn about it, take protective measures and psychologically remain sound. Its spread has shown the medical community the importance of prevention and precaution to be taken seriously. Only then we can save ourselves and serve the patients in distress.

\section{References}

1. Kondziolka D, Couldwell WT, Rutka JT. Introduction. On pandemics: the impact of COVID-19 on the practice of neurosurgery. Journal of Neurosurgery. 2020;1(aop):1-2.

2. Lakhdar F, Benzagmout M. Neurosurgery at war with the COVID-19 pandemic: patient's management from an African neurosurgical center. Acta Neurochirurgica. 2020.

3. Jean WC, Ironside NT, Sack KD, Felbaum DR, Syed HR. The impact of COVID-19 on neurosurgeons and the strategy for triaging non-emergent operations: a global neurosurgery study. Acta neurochirurgica. 2020:1-12.

4. Zoia C, Bongetta D, Veiceschi P, Cenzato M, Di Meco F, Locatelli D, et al. Neurosurgery during the COVID-19 pandemic: update from Lombardy, northern Italy; 2020.

5. Sun Y, Mao Y. Response to COVID-19 in Chinese neurosurgery and beyond. J Neurosurg. 2020;1(aop):1-2.

6. Lo YT, Teo NWY, Ang BT. Endonasal neurosurgery during the COVID-19 pandemic: the Singapore perspective. Journal of Neurosurgery. 2020;1(aop):1-3.

7. Amin-Hanjani S, Bambakidis NC, Barker FG, Carter BS, Cockroft KM, Du R, et al. COVID-19 and neurosurgical practice: an interim report. Journal of Neurosurgery. 2020;1(aop):1-2.

8. Mouchtouris N, Lavergne P, Montenegro TS, Gonzalez G, Baldassari M, Sharan A, et al. Telemedicine in Neurosurgery: Lessons Learned and Transformation of Care During the COVID-19 Pandemic. World Neurosurgery 2020;140:e387-e94. 9. Bambakidis NC, Tomei KL. Impact of COVID-19 on neurosurgery resident training and education. Journal of Neurosurgery. 2020;1(aop):1-2.

10. Tomlinson SB, Hendricks BK, Cohen-Gadol AA. Innovations in neurosurgical education during the COVID-19 pandemic: is it time to reexamine our neurosurgical training models? Journal of Neurosurgery. 2020;1(aop):1-2.

11. Chan DYC, Chan DTM, Mak WK, Wong GKC, Poon WS. Rongeurs, Neurosurgeons, and COVID-19: How do we protect health care personnel during neurosurgical operations in the midst of aerosol-generation from high-speed drills? Neurosurgery. 2020.

12. Gupta P, Muthukumar N, Rajshekhar V, Tripathi M, Thomas S, Gupta SK, et al. Neurosurgery and neurology practices during the novel COVID-19 Pandemic: A consensus statement from India. Neurology India. 2020;68(2):246. 